\title{
Silver Colloid and Silver Mirror Complex as Surface Enhanced Raman Substrate for Volatile Organic Compounds Analysis
}

\section{SARUNRAT INJAI-UEA ${ }^{1 *}$, NATPHICHON BUDTRI ${ }^{2}$ and WEERASAK LERTSIRIYOTHIN ${ }^{1}$}

'School of Agricultural Engineering, Institute of Engineering, Suranaree University of Technology,

111 University Avenue, Muang District, Nakhon Ratchasima, 30000, Thailand.

${ }^{2}$ School of Mechanical and Process System Engineering, Institute of Engineering, Suranaree University of Technology, 111 University Avenue, Muang District, Nakhon Ratchasima, 30000, Thailand.

*Corresponding author E-mail: Sarunrat.i@my.nsru.ac.th

http://dx.doi.org/10.13005/ojc/330540

(Received: July 07, 2017; Accepted: August 14, 2017)

\begin{abstract}
This research focuses on the development of Raman spectroscopy for determination of the low volatile concentration as toluene volatile and 2-Acetyl-2-thiazoline(2AT) volatile. The studies were divided into two techniques. The research was to develop surface enhanced Raman substrates (SERS) enhancedthe surface using silver metal for enhancement. In this part, there were two different types of the SERS suitable for FT-Raman. The first technique was silver colloid. This technique could build nanosilver particles, of which average size was $35.5-140.3 \mathrm{~nm}$. The detection limits were found to be at $4000 \mathrm{ppm}$ in 2 AT solution. The second techniques were the silver mirror and freezing technique. The detection limits for 2AT solution $0.2 \mathrm{ml}$ in vial were found to be at 4000 and 1000 ppm in the silver mirror. Results of the enhanced Raman spectra of volatile organic compounds (VOCs) contained in a sample showed that the concentration of 2AT was existed at higher level than thatof toluene. Therefore, the silver mirror type of SERS together with the FT-Raman could be used for determining 2AT in low concentration.
\end{abstract}

Keywords: SERS, Raman Spectroscopy, Silver mirror, Silver colloid, VOCs.

\section{INTRODUCTION}

Raman and Infrared spectroscopy are analytical techniquesfor studying and inspecting a spin or vibrate transition of functional group of molecular structures in solid, liquid, and gas states. The both techniques are different in processing.
The electrostatic irradiation with chemical moleculeInfrared spectroscopy technique is the infrared irradiation absorption processing as infrared light interacting with a molecule. It can be analyzed by measuringabsorption, emission, and reflection. Organic and inorganic chemistry are measured by this technique to determine functional 
groups in molecules. Raman spectroscopy technique is the techniqueof C.V. Raman who was honoredwith its inventoralong with K.S. Krishnan'. It is a scattering technique for detecting quantitative and qualitative samples. The superlow concentration of sample isa problem to be analyzed with the Raman spectrum. The surface enhanced Raman scattering (SERS) is one of the techniquesfor increasing Raman spectrograph.

SERS is the technique enhancing limited ability of the Raman spectroscopy for the determination of the superlow concentration in ppm level $^{2}$. They have reported that the limited importance of this technique is the low concentration of chemical volatile or gas. Zhang ${ }^{3}$ reported that the determination of low volume nitro toluene was detected by FT-Raman. The samples were in closed system because they could control volatile dispersion in the system. This method could not detect low volume in environment. Mosier-Boss ${ }^{4}$ has studied about a transient electrochemical surface-enhanced Raman spectroscopy (TEC-SERS) system.It is a continuous determined system so the system requires high volume of samples. Silver is a one of SER substrates to be air stable material ${ }^{5}$. Silver colloid was used be a SER substrate because it can give reproducible and sensitive analysis ${ }^{6}$. The SERS is not used for volatile measurement in full potential. Further more, the SERS technique is especially applied in food flavor which is the important thing for food quality and consumer acceptance. It can indicate composition characteristics, deterioration, and contamination such as changed flavor made by bacterial fermentation. The synthetic flavor is added to food products for making high quality food. Further more, SERS can also indicate low volume of 2-Acetry-1pyrroline in Jasmine rice (Kao Hom Mali) ${ }^{7-11}$. It is an aromatic compound havingthe same flavor as that in Pandanus. leaf. The volatile compound is also used in agricultural product of Thailand such as Kao Hom Mali and Kao Hom Prathumtani. They have identical appearance and same volatile compounds as 2-Acetyl-2-thiazoline.2-Acetyl-2thiazoline is also important aroma compound identified in cooked rice, beef flavor, and another food flavor $^{7,12-13}$. Further more, Toluene is the index of contamination in food industry. The SERS substrates also match each chemical form such as colloidal metal solution, metal coating on surface, and chemical reaction with metal.

This research was to study about SERS substrates of silver metal enhancing the Raman spectrograph and the development of SERS technique for determining the low volume and low concentration of samples. The SERS substrates were prepared from colloidal silver solution and silver mirror on glass slide. Toluene and 2AT were used to be samples then the SERS were determined by Raman spectroscopy.

\section{MATERIALS AND METHODS}

\section{Materials}

Silver nitrate $\left(\mathrm{AgNO}_{3}\right)$, Toluene $\left(\mathrm{C}_{7} \mathrm{H}_{8}\right)$, 2-Acetyl-2-thiazoline $\left(\mathrm{C}_{5} \mathrm{H}_{7} \mathrm{NOS}\right)$, Sodium hydroxide $(\mathrm{NaOH})$, ammonia, and glucose $\left(\mathrm{C}_{6} \mathrm{H}_{12} \mathrm{O}_{6}\right)$ were purchased from Sigma Aldrich. All water was deionized for experimental usage.

\section{Preparation of SERS substrates}

Silver colloid was obtained according to citrate reduction method or Lee and Meisel method ${ }^{14}$. It was prepared by adding $90 \mathrm{mg}$ of $\mathrm{AgNO}_{3}$ into $500 \mathrm{ml}$ of distilled water at $45^{\circ} \mathrm{C}$. The solution was mixed, boiled, and incessantly stirred on the hot plate. $10 \mathrm{ml}$ of $1 \%(\mathrm{w} / \mathrm{w})$ sodium citrate was added and continuously boiled for $1 \mathrm{~h}$. The solution was refluxed while it was boiled. Silver colloid was slowly cooled in room temperature. The silver colloid particle was measured by particle analyzer.

Silver mirror was obtained according to Tollens method ${ }^{15}$. It was prepared by putting $1 \mathrm{ml}$ of $1 \mathrm{~m} \mathrm{MAgNO}_{3}$ into the tube and adding concentrated ammoniato the solution. A brown precipitate will form and concentrated ammonia was added until the solution became clear. After that, $0.3 \mathrm{M}$ of $\mathrm{NaOH}$ solution was added to adjust $\mathrm{pH}(10.5 \pm 0.1)$. The solution was placed on the glass slideand then $1 \mathrm{ml}$ of $0.1 \mathrm{~m} \mathrm{M}$ glucose solution was added. The solution would turn to be yellow and brown then it became cloudy and dark before silver began to form on a glass slide. Silver mirror solution was reacted until the completed reaction. The glass slides were dried in room temperature. 


\section{Preparation of volatile samples}

2AT and toluene were used to be volatile samples for SERS testing. 2AT solution were prepared in DI water $(100,500,1000$, and 4000 $\mathrm{ppm}$ ), incubated at $60^{\circ} \mathrm{C}$ for $12 \mathrm{~h}$, and liquid was dropped in nitrogen for $5 \mathrm{~min}$. before testing. $0.2 \mathrm{ml}$ of toluene was prepared in vial, incubated at $60^{\circ} \mathrm{C}$ for $12 \mathrm{~h}$, and dropped in liquid nitrogen for $5 \mathrm{~min}$, before testing silver mirror substrates. $0.5 \mathrm{ml}$ of 2AT solution was added into $0 . \mathrm{ml}$ of silver colloid substrate solution in quartz cuvette and $0.5 \mathrm{ml}$ of toluene solution was also added.

\section{Raman Measurement}

The SERS and Raman spectra signals were collected by a Fourier transform Raman spectrometer (Bruker, Ram II) using 1064 nm excited Nd : YAG laser and 64 scan timesin room temperature. The spectral range between 4000 and $0 \mathrm{~cm}^{-1}$ was simultaneously used forrecording at resolution $4 \mathrm{~cm}^{-1}$ of FT-Raman apparatus. Data of Raman spectrawere analyzed by Opus program.

\section{RESULTS AND DISCUSSION}

\section{Characterization of SERS substrate development}

The development of silver colloid was used to be SERS by citrate reduction method. The solution of silver colloid was in yellow-gray color.It has been kept at $4^{\circ} \mathrm{C}$ for 2 months. The silver particles were measured by particle analyzer. They were nanoparticles size range between 35.5-140.3 $\mathrm{nm}$ and diameter of $113 \mathrm{~nm}$. The resultwas similar to Zhang ${ }^{16}$ who reported that the silver particlesizes with an average diameter of $13.8 \mathrm{~nm}$, and 35-500 $\mathrm{nm}$ of silver colloid particle sizes reported by $\mathrm{Kim}^{17}$. Further more, Prucek ${ }^{15}$ and $\mathrm{Lin}^{18}$ reported a range of nanosphere sizes between 430 to $1500 \mathrm{~nm}$.

The silver mirror was developed to be SERS by Tollens's method ${ }^{15}$. The silver mirror surface was emerged in a yellow-gray color like silver colloid color. Fig. 1 shows the surface roughness mirror. The result shows that the roughness of silver particles was not separated all over surface on glass slide. Similar to $\mathrm{Bu}^{19}$ who reported that the particle sizes were indicated to be nanoparticles size with $\mathrm{Au}$ and $\mathrm{Ag}$.

\section{Effect of SERS substrates on Raman scattering signal}

The chemical substance 2-Acetyl-2thiazoline (2AT) and toluene in this research were volatile compounds. The concentration of 2-Acetyl2-thiazoline was prepared from 100 to $1,000 \mathrm{ppm}$ and it was tested by FT-Raman spectroscopy. Fig. 2 shows the Raman spectrum of 2AT which was used

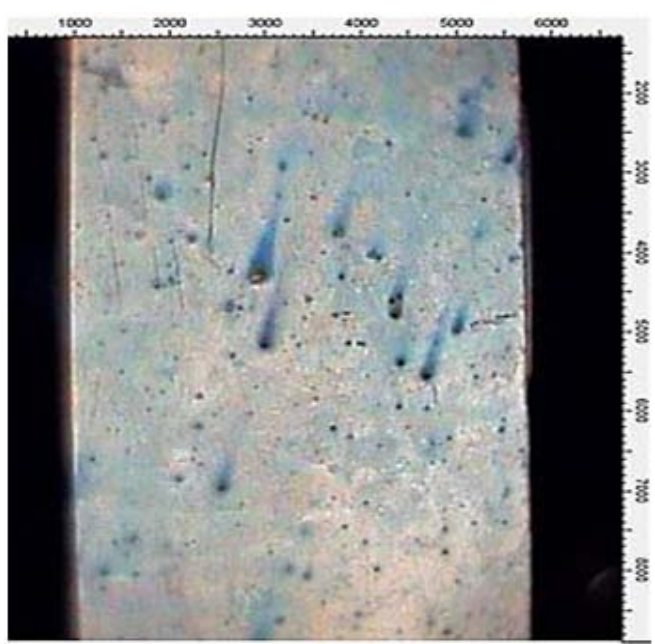

Fig. 1. A silver mirror surface fromRaman microscope

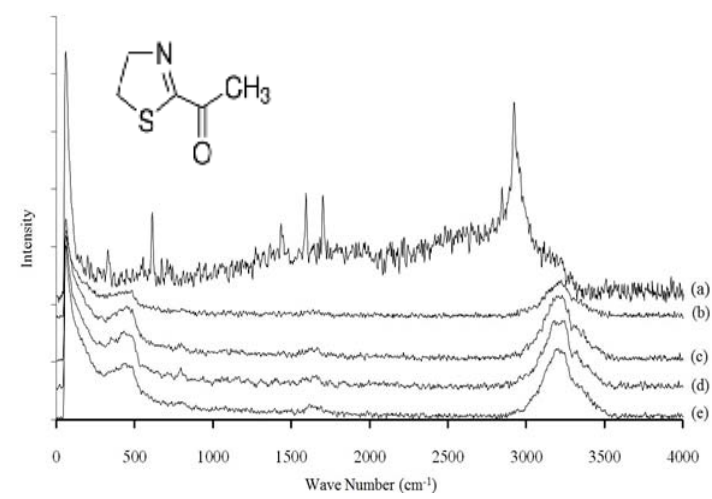

Fig. 2. Raman spectrum of 2AT on silver colloid (a) concentrate, (b) 100 ppm, (c) 500 ppm, (d) 1000 ppm, and (e) 4000 ppm

the silver colloid for the media to increase the signal of Raman spectrum. The results showed that Raman peak spectrum (Fig.2a) indicated 2AT vapor at wave number $1437 \mathrm{~cm}^{-1}$ and the peak shows the weak vibrational band and this band corresponds to C-N stretching motion. The spectrum of Raman peaks at $612 \mathrm{~cm}^{-1}, 1595 \mathrm{~cm}^{-1}$ and $1701 \mathrm{~cm}^{-1}$ show the strong vibrational bands. Their rendition are ring 
stretching, C-S stretching, $\mathrm{C}=\mathrm{C}$ stretching, and $\mathrm{C}=\mathrm{H}$ stretching, respectively. A very strong vibrational band is observed at $2913 \mathrm{~cm}^{-1}$. The band can be assigned to $\mathrm{CH}_{3}$ stretching vibration. The spectrum signals did not indicate the 2AT peak between 3000$3500 \mathrm{~cm}^{-1}$ but the signal was shifted to $3222 \mathrm{~cm}^{-1}$ of wave number. They might also be affected by laser heat. $0.5 \mathrm{ml}$ of silver colloid and $0.5 \mathrm{ml}$ of 2-Acetyl2-thiazoline were mixed together. The peak spectra of 2AT did not clearly appear at 100, 500, and 1000 ppm. The concentration of $4000 \mathrm{ppm}$ of 2AT did not show the peak signal at $612 \mathrm{~cm}^{-1}, 1437 \mathrm{~cm}^{-1}$, $1595 \mathrm{~cm}^{-1}, 1701 \mathrm{~cm}^{-1}$ and $2913 \mathrm{~cm}^{-1}$ but the signals were shifted as shown in Fig. 3. Because, the colloidal silver solution was precipitated and accumulated for 3-4 seconds. Eventually, the sample was not continuously homogenous to Raman spectrum measurement and similar to the report of Munro ${ }^{14}$ who found the colloidal silver nanocrystal structure in low dispersion, precipitation, and accumulation. Raman spectrum shift was found with a minor bathochromic shift to high wave length for 2,10,15, and 90 min. such as the initial measurement at the peak of $1390 \mathrm{~cm}^{-1}$. The spectrum shift was changed to the peak of 1395 , 1400 , and $1400 \mathrm{~cm}^{-1}$ for 10,15 , and $90 \mathrm{~min}$, respectively. The colloidal silver technique was suitable for stirring in suspension. Zhang ${ }^{3}$ reported the measurement of 2,4,6 trinitrotoluene (TNT) using confocal microprobe Raman system at laser source $532 \mathrm{nmby}$ adding air bubbles to flow through polymer tube into colloidal silver solution. The result showed that the minimum concentration for detectionwas a $10 \mu \mathrm{g} / \mathrm{l}$. Lin $^{18}$ reportedthat the optimum SER signal was obtained at an excitation wavelength of $532 \mathrm{~nm}$ with a nanosphere size of $1000 \mathrm{~nm}$.

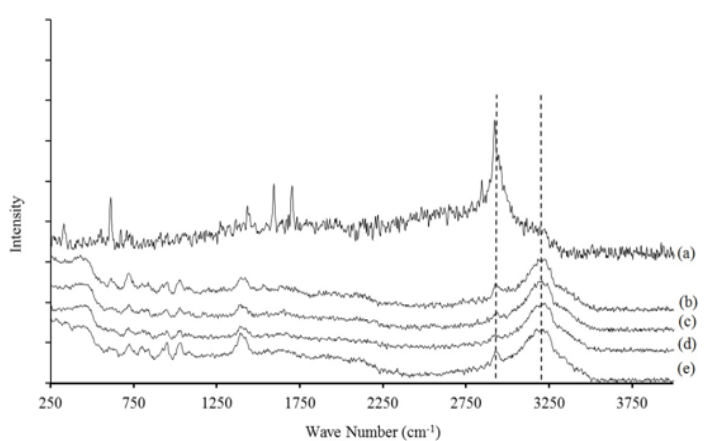

Fig. 3. Raman spectrum of $2 A T$ at concentration on (a) concentrate, (b) $100 \mathrm{ppm}$, (c) $500 \mathrm{ppm}$, (d) 1000 ppm, and (e) 4000 ppm
Silver mirror technique was used in this research measured by using toluene and 2AT. Toluene was absorbed by silver mirror glass at temperature $60^{\circ} \mathrm{C}$ and was measured by FT-Raman spectroscopy. Toluene peak spectrum on silver mirror glass was not shown as seen in Fig. 4 because molecules of toluene in gas state had low opportunity for collisions and binds within silver mirror. The experimentation was closed system and gas molecularity was also in low mobilization. The technique for measurement was immediate freezing technique binding the molecule of toluene within the silver mirror. The procedures were firstly preparing silver mirror glass and toluene which was contained in vial,and then immersing them to liquid nitrogen before measuring. The results showed that Raman peak spectrum indicated toluene vapor at $783 \mathrm{~cm}^{-1}, 1030 \mathrm{~cm}^{-1}, 1211 \mathrm{~cm}$ ${ }^{1}, 1611 \mathrm{~cm}^{-1}$, and $3056 \mathrm{~cm}^{-1}$. This technique increased by 5 times of spectrum signals compared with toluene Raman spectrum of toluene within silver mirror without immersing liquid nitrogen. Raman spectrum of 2AT in gas state indicating the

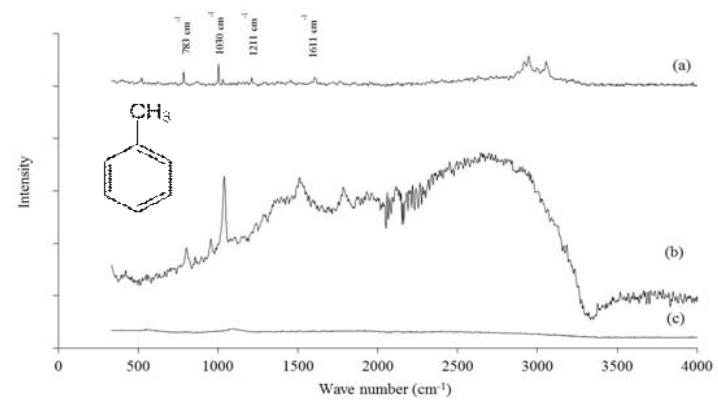

Fig. 4. Raman spectrum of pure toluene (a), toluene on silver mirror glass by freezing technique (b), and without freezing technique (c)

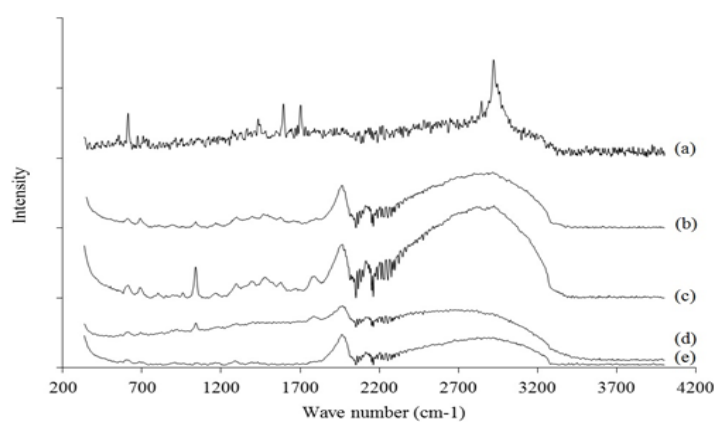

Fig. 5. Raman spectrum of 2AT on silver mirror glass using silver mirror glass freezing technique according to concentration (a) concentrate (b) $100 \mathrm{ppm}$, (c) 500 ppm, (d) 1000 ppm, and (e) 4000 ppm 
measurement of concentration between $612 \mathrm{~cm}^{-1}$ and $2913 \mathrm{~cm}^{-1}$ with the minimum concentration of 2AT at $1000 \mathrm{ppm}$ was from 100, 500, 1000, and 4000 ppm as shown in Figure. 5.

Wong ${ }^{20}$ reported that nano-pillar substrate development using Raman microscope Laser source at $633 \mathrm{~nm}$ could detect a minimum of $0.4 \%$ of ethanol and $0.8 \%$ of acetone by sample flow through system. This technique was reported by Zhang $^{3}$ that it showed the determination of volatile organic compounds in low concentration (ppm) as shown in table 1. Raman spectroscopy was remarkable for determining the chemical volatile in low concentration. It could specify chemical structures and chemical compounds. This research found that the SERS developing silver mirror glass with freezing were our techniques. They could support the FT-Raman laser source at $1064 \mathrm{~nm}$ as low activated energyof Raman spectroscopy. They could also detect and measure the low volatile compounds $(0.2 \mathrm{ml})$ in closed system. The SERS were used in this experiment for their practical production at a low price.

\section{CONCLUSIONS}

In this study, silver colloid and silver mirror were used to be a SERS for increasing the activated energyof Raman spectroscopy. Silver colloids were prepared in solution as nanoparticles size range between of $35.5-140.3 \mathrm{~nm}$ and diameter of $113 \mathrm{~nm}$. The increasing Raman spectrum of 2AT in silver colloids was not changed when compared with Raman spectrum of 2AT. Silver mirror was prepared by Tollens method on glass slide and the determination of toluene and 2AT. They were both used for an immediate freezing technique and unfreezing. Raman spectrum increased by almost 5 times of 2AT. They could measure the volatile compounds $(0.2 \mathrm{ml})$ in low volume and a closed system.

\section{ACKNOWLEDGMENTS}

This work was supported by National Research Council of Thailand (NRCT), Office of the Higher Education Commission (OHEC), and Suranaree University of Technology (Nakhon Ratchasima, Thailand). 


\section{REFERENCES}

1. Raman, C. V.; Krishnan, K. S. Nature.1928, 121, 501-502.

2. Deschaines, T. O; Wieboldt, D. Practical Applications of Surface-Enhanced Raman Scattering (SERS). Technical Note: 51874, Thermo Fisher Scientific, Madison, WI, USA., 2010.

3. Zhang, C.; Wang, K.; Han, D.; Pang, Q.Spectro Acta Part A: Molecur and Biomolecur Spectro. 2014, 122, 387 -319.

4. Sharma, B.; Frontiera, R. R.; Henry, A. I.; Ringe, E.; Van Duyne, R. P. Materialstoday. 2012, 15, 16-25.

5. Munro, C. H.; Smith, W. E.; Garner,M.; Clarkson, J.; White, P. C. Langmuir. 1995, 11, 3712-3720.

6. Mosier-Boss, P. A.; Lieberman, S. H. Anal.ChimicaActa. 2003, 488, 15-23.

7. Buttery, R. G.; Ling, L. C.; Juliano, B. O.; Turnbaugh, J. G. J. Agric. Food. Chem.1983, 31, 823-826.

8. Jezussek, M.; Juliano, B. O.; Schieberle, P.J. Agric. Food. Chem.2002, 50, 1101-1105.

9. Laksanalamai, V.; Ilangantileke, S.Cere. Chem. 1993, 70, $381-384$.
10. Paule, C. M.; Power, J. J. food sci. 1989, 54, 343 - 347.

11. Mahattanatawee, K.; Rouseff, R. L. Food Chem. 2014, 154, 1-6.

12. Fang, M. C.; Cadwallader, K. R. J. Agric. Food Chem. 2014, 62, 8808-8813.

13. Plancken, A. J.; Tonsbeek, C. H. T.; Copier, H. J. Agric. Food Chem.1971, 19, 1014-1016.

14. Munro, C.H.; Smith, W.E.; Garner, M.; Clarkson, J.; White, P.C. Langmuir. 1995, 11, 3712-3720.

15. Prucek, R.; Ranc, V. C.; Balzerová, O.; Panácêk, A.; Zboøil, R.; Kvítek, L. Materi. Res. Bul. 2014, 50, 63-67.

16. Zhang, Z.;Wu, Y.;Wang, Z:;Zou, X.; Zhao, Y:; Sun, L. Materi. Sci. Eng. C. 2016, 69, 462-469.

17. Kim, K.; Jang, H. J.; Shin, K. S. Royal. Soci. Chem. 2008, 134, $308-313$.

18. Lin, W.C.; Liao, L. S.; Chen, Y. H.; Chang, H.C.; Tsai, D. P.; Chiang, H. P. Plasmonics. 2011, 6, 201-206.

19. Bu, Y.; Park, S. J.; Lee, S. W. Current. Appl. Phys. 2014, 14, 784-789.

20. Wong, C. L.; Dinish, U. S.; Schmidt, M. S.; Olivo, M. AnalyticaChimicaActa. 2014, 844, 54-60. 